\title{
Е.А. Завгородняя
}

Гжельский государственный университет, 140155, Московская область, Российская Федерация

\section{Обучение на рабочем месте как важный элемент системы профессионального образования Республики Корея}

Статья посвящена такому важному элементу системы профессионального образования Республики Корея, как обучение на рабочем месте, которое в настоящее время не является обязательным, в частности, из-за отсутствия стандартов качества и четкой нормативно-правовой базы. Автором описываются преимущества введения обязательного обучения на рабочем месте для студентов высшего профессионального образования, такие как обеспечение насыщенной учебной среды, сглаживание процесса перехода от обучения к работе, практическая польза для работодателя и обеспечение соответствия профессионального образования потребностям рынка труда. Рассматриваются проблемы, с которыми сталкивается система профессионального образования Республики Корея при внедрении обязательного обучения на рабочем месте, и пути их решения, предпринимаемые правительством этой страны. Особо делается акцент на необходимости и вариантах более тесного взаимодействия между учебными заведениями профессионального образования и компаниями-работодателями с целью достижения максимального положительного эффекта от организации обучения на рабочем месте.

Ключевые слова: Республика Корея, профессиональное образование, младший колледж, компания-работодатель, трудоустройство, обучение на рабочем месте

ССЫЛКА НА СТАТЬЮ: Завгородняя Е.А. Обучение на рабочем месте как важный элемент системы профессионального образования Республики Корея // Педагогика и психология образования. 2019. № 3. C. 86-93. DOI: 10.31862/2500297Х-2019-3-86-93 


\section{E. Zavgorodnyaya}

Gzhel State University, Moscow region, 140155, Russian Federation

\section{Work-based learning as an important element of vocational education system in the Republic of Korea}

The article deals with such an important segment of vocational education system of the Republic of Korea as work-based learning which is currently not obligatory particularly due to the absence of quality standards and clear legal base. The article describes advantages of work-based learning for vocational education students, such as organization of proper learning environment, smoothing of transfer period from learning to work, practical benefits for an employer and ensuring compliance of vocational education to the requirements of labor market. The article describes problems which vocational education system the Republic of Korea is facing while implementing mandatory work-based learning and the ways of solution of these problems taken by the Government of the country. Especially the article emphasizes the necessity and variants of closer interaction between vocational institutions and employing companies in order to achieve the maximum positive effect from the organization of training at the workplace.

Key words: Republic of Korea, vocational education, junior college, companyemployer, employment, work-based learning

CITATION: Zavgorodnyaya E.A. Work-based learning as an important element of vocational education system in the Republic of Korea. Pedagogy and Psychology of Education. 2019. No. 3. Pp. 86-93. DOI: 10.31862/2500-297X-2019-3-86-93

В настоящее время обучение на рабочем месте для студентов т.н. «младших колледжей» (анг. junior colleges) - основной разновидности высших учебных заведений профессионального образования Республики Корея - не является обязательным. По поводу организации подобного 
обучения существуют различные договоренности о сотрудничестве между младшими колледжами и компаниями-работодателями, причем в то время как некоторые вузы предлагают индивидуальные программы обучения, соответствующие потребностям конкретных компаний, другие имеют очень слабые связи с представителями рынка труда.

Контроль качества обучения на рабочем месте варьируется в зависимости от учебного заведения и часто является чисто формальным. Когда обучение на рабочем месте соответствует интересам отдельных компаний, слабо или практически не контролирующих качество данного обучения, существует риск того, что студенты могут быть использованы в качестве дешевой неквалифицированной рабочей силы или же будут приобретать узкоспециализированные навыки, необходимые для нужд конкретной фирмы.

Задача обеспечения качества обучения на рабочем месте в программах высшего профессионального образования Республики Корея также была признана Корейским научно-исследовательским институтом профессионального образования и обучения (KRIVET), который разрабатывает базовые рекомендации для компаний, предлагающих обучение на рабочем месте. Основополагающей идеей является сделать обучение на рабочем месте обязательным в программах для младших колледжей и обеспечить такие условия, при которых обучение на рабочем месте поддерживалось бы стандартами качества и четкой правовой базой.В работах экспертов, исследующих вопросы организации профессионального образования в Республике Корея, в частности, С.-К. Chaе и J.-H. Chung, приводятся четыре основных аргумента в поддержку данной концепции. Во-первых, обучение на рабочем месте дает большие преимущества студентам и компаниям. Во-вторых, оно не только приносит пользу учащимся, но и способствует улучшению отношений между учебными заведениями и компаниями-работодателями. В-третьих, успешный международный опыт демонстрирует возможность и преимущества данного вида обучения. Наконец, соответствующая поддержка со стороны государства может стимулировать и помогать компаниям более активно предлагать обучение на рабочем месте [2]. Остановимся более подробно на каждом из этих аргументов.

1. Обучение на рабочем месте дает большие преимущества студенmaм $и$ компаниям. Существует четыре основных преимущества, как с точки зрения студентов, так и работодателей, для того, чтобы организовать часть программы обучения именно на рабочем месте, а не в стенах учебного заведения, которые были отмечены в обзоре Организации экономического сотрудничества и развития (OECD) [5]: 
Обеспечение насыщенной учебной среды, т.к. студенты получают реальный опыт на рабочем месте. Это облегчает для них приобретение сложных навыков, поскольку они могут использовать современное оборудование и обучаться у сотрудников компании использованию новейших технологий. Это также более рентабельно, чем покупка дорогостоящего оборудования самими вузами, что является актуальным вопросом в связи с быстрыми изменениями технологий. Многие навыки (например, работа в команде, управление конфликтами) лучше усваиваются непосредственно на реальном рабочем месте, чем в искусственно смоделированной в стенах учебного заведения рабочей среде.

Сглаживание процесса перехода от обучения к работе. На рабочем месте работодатели и студенты находятся в тесном контакте, взаимодействуя друг с другом не только для решения поставленных задач и выполнения профессиональных обязанностей, но и в рамках неформального общения. Характеристики сотрудников, представленные в этом контексте, имеют решающее значение для эффективности будущей работы, т.к. работодатели получают представление о положительных и отрицательных качествах потенциальных кандидатов и отмечают лучших из них. В свою очередь, студенты могут узнать о непосредственных условиях работы, предлагаемых как минимум одним потенциальным работодателем.

Реальная польза для работодателя. Студенты, выполняющие полезную работу в ходе обучения на рабочем месте, приносят работодателю практическую выгоду, которая особенно заметна при длительном сроке и менее проявляется при коротком сроке (только если стажеры не выполняют неквалифицированные задания, но такой опыт обучения нельзя считать продуктивным). Их вклад обычно увеличивается с опытом и зависит также от того, как организована их работа.

Обеспечение соответствия профессионального образования потребностям рынка труда. Готовность работодателей предлагать рабочие места для обучения студентов является показателем их поддержки соответствующей профессиональной программы. Работодатели будут особенно заинтересованы в обучении на рабочем месте в условиях нехватки рабочей силы - как в связи с тем, что студенты заняты на производстве и приносят практическую пользу, так и потому, что они получают перспективу реального трудоустройства в будущем.

2. Обязательное обучение на рабочем месте существенно улучшает отношения между учебными заведениями и компаниями-работодателями. Меняется динамика системы профессионального образования, т.к. появляется гарантия, что деятельность вузов будет сфокусирована 
не только на конкурентной борьбе за студентов и внутренней институциональной динамике, но и на удовлетворение потребностей рынка труда в подготовке специалистов определенных навыков. Введение обязательного обучения в системе профессионального образования гарантирует, что все учебные заведения будут устанавливать партнерские отношения с компаниями даже в тех случаях, когда они предлагают популярные у студентов учебные программы, не имеющие высокой востребованности на рынке труда. По мере того, как программы профессионального образования будут все более отвечать потребностям рынка труда, а вузы будут систематически связываться с компаниями-работодателями, качество и статус программ будут совершенствоваться, особенно в глазах местных работодателей. В частности, исследование системы профессионального образования Испании подтверждает, что проведенная в этой стране реформа, сделавшая обучение на рабочем месте обязательным, произвела положительный эффект. Она вывела отношения между учебными заведениями и компаниями-работодателями на новый уровень взаимодействия и способствовала более успешному трудоустройству выпускников вузов профессионального образования [4].

Обязательное обучение на рабочем месте в программах высшего профессионального образования должно также принести пользу преподавательскому составу. Поддержание технических навыков преподавательского состава на современном уровне является серьезной проблемой во многих странах. В Республике Корея преподаватели в младших колледжах не обязаны иметь опыт работы по предмету, который они преподают. Поскольку требования на рабочих местах быстро меняются, многие преподаватели просто не успевают осваивать современные технологии и методы работы в компаниях. Если бы обучение на рабочем месте было обязательным, преподавательский состав уделял бы больше внимания информационно-разъяснительной работе с компаниямиработодателями, что дало бы им возможность постоянно быть в курсе их актуальных запросов. В частности, для поиска возможности организации обучения на рабочем месте, преподавателям было бы необходимо так или иначе налаживать контакты с компаниями и убеждать их в ценности студентов, участвующих в программе, что привело бы к более глубокому пониманию профиля деятельности компаний и их насущных потребностей. Чтобы контролировать качество обучения на рабочем месте, преподавателям необходимо поддерживать тесный контакт с компаниями, в то время как по завершении курса обучения студенты также осуществляют такой контроль посредством взаимной обратной связи. Например, в Дании обязательное трудоустройство рассматривается многими преподавателями как важное средство обеспечения их осведомленности о современных требованиях к рабочему месту [3]. 
Можно также отметить, что когда обучение на рабочем месте является необязательным, студентам, лично знакомым с людьми, работающими в соответствующем секторе производства, легче найти возможность трудоустройства, в то время как те, у кого нет таких связей, могут испытывать трудности. Кроме того, когда обучение на рабочем месте не является частью программы (например, обучение во время каникул), находящиеся в сложном материальном положении студенты могут предпочесть найти оплачиваемую работу, не связанную с их учебой. Обязательное обучение на рабочем месте гарантирует, что все студенты получают преимущества от трудоустройства. Наконец, косвенная выгода для студентов заключается в том, что программы с обязательным обучением на рабочем месте, вероятно, будут в большей степени соответствовать рынку труда и, следовательно, улучшать перспективы занятости [2].

3. Эффективность введения обязательного обучения студентов на рабочем месте подтверждается опытом большинства стран Евросоюза (Германии, Дании, Швеции, Испании и т.д.), равно как и США и Японии [1]. Конечно, этот процесс всегда сопряжен с трудностями, особенно в условиях отсутствия традиции сотрудничества между учебными заведениями и компаниями-работодателями в Республике Корея. Но, учитывая возможные перспективы, это задача, которую страна хочет и пытается решить.

4. Оказание поддержки мальм и средним предприятиям в организации обучения на рабочем месте. Несмотря на вышеуказанные преимущества и перспективы, предложение обучения на рабочем месте создает различные проблемы для компаний. Это связано с дополнительными административными задачами, и опытные работники должны выделять часть своего времени для наблюдения за учащимся, задача, которая требует управленческих и обучающих навыков. Это бывает особенно проблематично для малых и средних предприятий (МСП), представляющих около 90\% от общего числа предприятий в стране, которым, в отличие от крупных корпораций, может не хватать административного и управленческого потенциала для решения этих дополнительных задач. В результате, привлечение МСП к организации обучения на рабочем месте представляет собой определенную проблему, требующую особого подхода.

Для решения этой задачи Министерство занятости и труда Республики Корея в 2003 г. внедрило программу создания Консорциумов профессионального обучения для малых и средних предприятий после пилотного проекта, запущенного в 2001 г. В задачи консорциумов входит определение потребностей в обучении на МСП и разработка программ обучения для своих сотрудников. Консорциумы также 
занимаются административными задачами, связанными с запросами государственных субсидий на обучение, причем правительство РК субсидирует расходы на персонал и обучение. Оценка учебных консорциумов показала, что после многообещающего пилотного проекта широкомасштабная реализация программы была менее успешной в привлечении МСП. Основная причина этого заключалась в том, что консорциумы были сосредоточены большей частью на работе с учебными заведениями, а потенциальные работодатели в конечном итоге потеряли интерес к этой инициативе [6]. Это произошло потому, что согласно внутренним правилам консорциумов акцент делался на прохождении обучения в учебных заведениях, а не на рабочем месте. Это говорит о том, что при адекватной поддержке МСП все-таки могли бы предложить обучение на рабочем месте студентам. Таким образом, программа Консорциумов профессионального обучения для МСП и уроки, извлеченные из ее реализации, могут быть полезны при разработке инициативы, которая может помочь МСП предложить обучение на рабочем месте для студентов вузов профессионального образования.

Также стоит отметить, что отсутствие четкой правовой базы, в частности, отсутствие системы страхования от несчастных случаев на производстве, часто становится непреодолимым препятствием для большинства компаний Республики Корея, в принципе готовым к организации обучения на рабочем месте. Решением могла бы стать разработка такой нормативно-правовой базы с конкретными контрактами, предлагаемыми обучающимся на рабочем месте.

Как утверждается в обзоре ОЭСР, обязательная военная служба также является препятствием для корейских компаний предлагать обучение на рабочем месте. Студентам, которые не служили в вооруженных силах до поступления в вуз, как правило, приходится проходить военную службу во время или после учебы, что усложняет сохранение бывших учащихся в качестве работников [5]. Чтобы решить эту проблему, многие студенты выбирают службу в армии в середине своей учебы. Таким образом, организация обучения на рабочем месте в конце программы обучения представляется более разумной, поскольку в более зрелом возрасте студенты будут лучше подготовленными, и это облегчит их переход на работу.

Подводя итог, следует отметить, что обучение на рабочем месте приобретает все более значимое место в сегменте профессионального образования Республики Корея, и положительный опыт данной страны целесообразно учитывать в процессе реализации компетентностного подхода как основного направления модернизации системы образования в Российской Федерации. Несмотря на то, что производственная 
практика является неотъемлемой частью системы профессионального образования в нашей стране, все-таки большей частью она нацелена на отработку практических навыков учащихся, предполагая, что основной теоретический массив студенты получают в стенах вуза. Что касается Республики Корея, то там обучение на рабочем месте предполагает, что наряду с практическими навыками студенты получают и довольно существенный массив теоретических знаний, особенно актуальных при работе в конкретной отрасли промышленности [6]. Именно на этот нюанс стоит обратить внимание при разработке программ производственной практики в нашей стране.

\section{Библиографический список / References}

1. Трегубова Т.М., Масалимова А.Р. Зарубежные модели дополнительного профессионального образования: теоретико-методологический анализ: Научно-методическое пособие. Казань, 2013. [Tregubova T.M., Masalimova A.R. Zarubezhnye modeli dopolnitelnog oprofessionalnogo obrazovaniya: teoretiko-metodologicheskiy analiz [Foreign models of additional vocational education: Theoretical and methological analysis]. Scientificmethodological guide-book. Kazan, 2013. (In Russ.)]

2. Chae C.-K., Chung J.-H. Pre-employment vocational education and training in Korea. The World Bank, 2016. SP Discussion Paper No. 0921.

3. Danish Agency for Higher Education and Educational Support (2012), Skills beyond School: OECD review of post-secondary vocational education and training - National Background Report for Denmark. URL: http:/www.oecd. org/education/skills-beyond-school/SBS\%20Denmark.pdf

4. Homs O. La Formación Profesional en España, Hacia la Sociedad del Conocimiento. Obra Social, 2008.

5. Kuczera M., Kis V., Wurzburg G. OECD Reviews of vocational education and training: A learning for Jobs Review of Korea 2009. OECD Publishing, 2009.

6. Lee K.-W. Productivity increases in SMEs: With special emphasis on in-service training of workers in Korea. The World Bank, 2016. SP Discussion Paper. No. 0917.

Статья поступила в редакцию 02.04.2019, принята к публикации 22.06.2019

The article was received on 02.04.2019, accepted for publication 22.06.2019

Сведения об авторе / About the author

Завгородняя Елена Артёмовна - аспирант кафедры психологии и педагогики, Гжельский государственный университет, Московская область

Elena A. Zavgorodnyaya - post-graduate student of the Departments of Psychology and Pedagogy, Gzhel State University, Moscow region

E-mail: zavgorodni@mail.ru 